Revised Version 2 July 2008

\title{
Geometries of Third-Row Transition-Metal Complexes from Density-Functional Theory.
}

Michael Bühl, ${ }^{* a}$ Christoph Reimann, ${ }^{b}$ Dimitrios A. Pantazis, ${ }^{b}$ Thomas Bredow, ${ }^{b}$ Frank Neese ${ }^{* b}$ School of Chemistry, North Haugh, University of St. Andrews, St. Andrews, Fife KY16 9ST, UK, Fax: +(44)(0)1334 463808, E-mail: buehl@st-andrews.ac.uk

Universität Bonn, Institut für Physikalische und Theoretische Chemie, Wegelerstr. 12, D-53115 Bonn, Germany, FAX: +(49) 228/73-9064 E-Mail: neese@thch.uni-bonn.de

\begin{abstract}
A set of 41 metal-ligand bond distances in 25 third-row transition-metal complexes, for which precise structural data are known in the gas phase, is used to assess optimized and zero-point averaged geometries obtained from DFT computations with various exchange-correlation functionals and basis sets. For a given functional (except LSDA) Stuttgart-type quasi-relativistic effective core potentials and an all-electron scalar relativistic approach (ZORA) tend to produce very similar geometries. In contrast to the lighter congeners, LSDA affords reasonably accurate geometries of 5d-metal complexes, as it is among the functionals with the lowest mean and standard deviations from experiment. For this set the ranking of some other popular density functionals, ordered according to decreasing standard deviation, is BLYP $>$ VSXC $>$ BP86 $\approx$ BPW91 $\approx$ TPSS $\approx$ $\mathrm{B} 3 \mathrm{LYP} \approx \mathrm{PBE}>\mathrm{TPSSh}>\mathrm{B} 3 \mathrm{PW} 91 \approx \mathrm{B} 3 \mathrm{P} 86 \approx \mathrm{PBE}$ hybrid. In this case hybrid functionals are superior to their non-hybrid variants. In addition, we have re-investigated the previous test sets for 3d- (Bühl M.; Kabrede, H. J. Chem. Theory Comput. 2006, 2, 1282-1290) and 4d- (Waller, M. P.; Bühl, M. J. Comp. Chem. 2007, 28, 1531-1537) transition metal complexes using all-electron scalar relativistic DFT calculations in addition to the published non-relativistic and ECP results. For this combined test set comprising first-, second-, and third-row metal complexes, B3P86 and PBE hybrid are indicated to perform best. A remarkably consistent standard deviation of around $2 \mathrm{pm}$ in metal-ligand bond distances is achieved over the entire set of d-block elements.
\end{abstract}

\footnotetext{
${ }^{a}$ University of St. Andrews

${ }^{b}$ University of Bonn
} 


\section{Introduction}

Quantum-chemical calculations require additional approximations to account for relativistic effects when heavier atoms are present. One of the most popular of these approximations is the pseudopotential or effective core potential (ECP) approach, ${ }^{1}$ where the innermost electrons are not treated explicitly, but subsumed into a specially designed, mean potential acting upon the outer electrons. This ECP can be adjusted numerically such as to account for the leading scalar relativistic effects in the core region even in an otherwise non-relativistic calculation. Pseudopotentials have fertilized many fields of applied theoretical chemistry, and are now in widespread use.

Initially designed at the Hartree-Fock level, ECPs and their corresponding valence basis sets were readily embraced by the ever growing community that uses density functional theory (DFT) in its many flavors. Computational transition-metal chemistry in particular has benefited a lot from this development. ${ }^{2}$ From the competing brands of ECPs, two suppliers appear to dominate this market, namely the Hay-Wadt ${ }^{3}$ and Stuttgart-Dresden ${ }^{4}$ variants, ${ }^{1}$ both of which have performed very well in countless validation studies. In contrast, the choice of a suitable exchange-correlation functional from the plethora of vendors is more difficult, firstly because of the vast supply of such functionals, and secondly, because their performance may strongly depend on the particular application.

Regardless of their nature, such applications need accurate molecular structures as inputs. We have become interested in assessing the ability of modern DFT methods to reproduce gas-phase geometries of transition-metal complexes in a straightforward, consistent manner. For this purpose, we selected sizeable test sets of target molecules, for which reasonably precise and, presumably, accurate structural data is available from gas-phase electron diffraction (GED) or microwave (MW) spectroscopy. In the spirit of Helgaker et al, ${ }^{5,6}$ the performance of several density-functional/basisset combinations is assessed by correlating computed with experimental bond distances and analyzing the resulting mean and standard deviations. Only bond distances refined experimentally to a precision better than $1 \mathrm{pm}$ are included in this analysis. We have previously reported such assessments for first- ${ }^{7}$ and second-row ${ }^{8}$ transition metal complexes, which have revealed subtle differences in the performance of standard density functionals for these two sets. We now extend these studies to complexes from the third transition row. This now allows comprehensive performance tests for computational methods to describe molecular structures that contain metal centers from the whole d-block. 
Not only quantum-chemical models such as specific exchange-correlation functionals can be tested this way, but also the approximations made to account for relativity. There is growing interest to go beyond the ECP model and to describe all electrons in an explicit relativistic treatment. While full four-component relativistic calculations are still extremely involved and feasible only for atoms and the smallest molecules, two-component variants have evolved to a point that allows their rather routine application to sizeable systems. In practice, unless the elements are very heavy the effect of spin-orbit coupling on molecular geometries is limited. ${ }^{9,10}$ This suggests that more straightforward and computationally less involved one-component scalar relativistic approaches are the methods of choice for all-electron calculations on third-row transition metals. The advantages of all-electron treatments are obvious if total electron densities are to be computed ${ }^{11}$ or - in particular - if spectroscopic properties are computed that depend on the inner-shell electrons or the nodal properties of the valence orbitals. This concerns for example X-ray absorption, ${ }^{12}$ Mössbauer ${ }^{13}$ and nuclear magnetic ${ }^{14}$ or electron paramagnetic resonance ${ }^{15,16}$ properties. However, rather special basis sets must be used in all-electron scalar relativistic calculations that are consistent with the relativistic treatment invoked. Such special basis sets have been designed previously for calculations within the Douglas-Kroll-Hess (DKH) ${ }^{17}$ or the zero'th order regular approximation (ZORA) $)^{9,18}$ treatments. However, as far as Gaussian basis sets are concerned, these basis sets are generally contracted and therefore computationally expensive. We have therefore recently reported a series of segmented all electron relativistic (SARC) basis sets for third row transition metals that can be applied together with the DKH2 and ZORA approaches. ${ }^{19}$ Atoms from the first three rows are treated with relativistic recontractions of the Karlsruhe split valence (SV), triple-zeta valence (TZV) or quadruple-zeta valence (QZVP) all-electron basis sets. ${ }^{20,21,22}$

In ref 19 test calculations for geometries of small transition metal hydrides, ionization potentials and binding energies were calculated with the new basis sets and either B3LYP density functional or coupled-cluster with single-, double- and perturbative triple excitations (CCSD(T)) methods. Here we take the opportunity to compare the performance of all-electron scalar relativistic DFT calculations with ECPs for a much broader range of functionals relative to precise gas phase structural data of polyatomic molecules. Thus, the present study serves the triple purpose of: (a) evaluating the performance of ECP based DFT calculations for the prediction of geometries of third-row transition metals, (b) to compare the relative merits of ECP based and scalar-relativistic all-electron calculations throughout the d-block and (c) to evaluate the performance of the SARC all-electron basis sets for 3d-, 4d-, and 5d-transition metal geometries. 

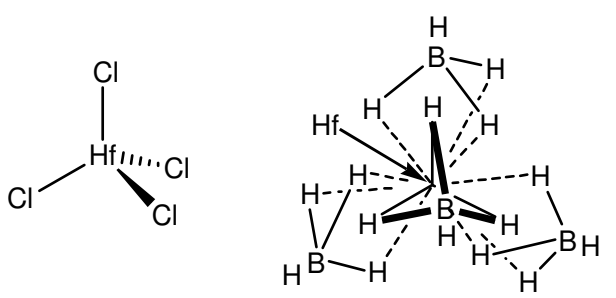<smiles>Cl[Te](Cl)(Cl)(Cl)Cl</smiles><smiles>[1H][Te]([1H])([1H])(F)(F)F</smiles><smiles>F[W](F)(F)(F)(F)O[W]</smiles>

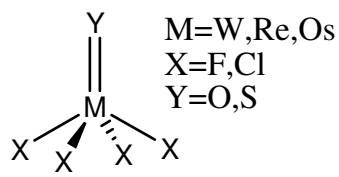<smiles>C[14C](C)(C)[14C](C)(C)C</smiles><smiles>O=[W]([O-])([O-])([O-])[O-]</smiles><smiles>[3H]C1CC2CC3(CC2C1)CC3Nc1ccccc1</smiles><smiles>F[Te](F)(F)[Te](F)(F)(F)(F)F</smiles><smiles>C[Po](=O)(=O)[O-]</smiles><smiles>C[R9]1(=O)[CH][CH]1</smiles><smiles>[O-][Cl+3]([O-])([O-])[O-]</smiles><smiles></smiles><smiles></smiles><smiles>F[P-](F)(F)[Pb](F)(F)[Pb-]</smiles>

\section{Scheme 1}

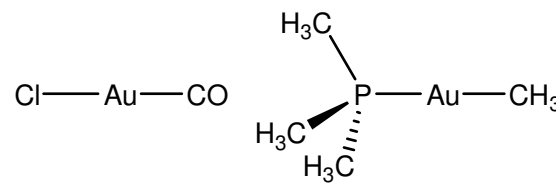

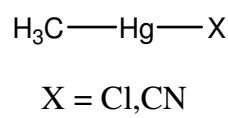<smiles>FC(F)(F)[Hg]C(F)(F)F</smiles>

The test set for the $5 \mathrm{~d}$ metals is shown in Scheme 1. It comprises complexes of the metals from Hf to $\mathrm{Hg}$, for which quite precise experimental data are available from gas-phase electron diffraction (GED) and/or microwave spectroscopy (MW). This test set should be diverse enough to cover a wide range of bonding situations, from complexes of high-valent early transition metals with electronegative ligands to electron-rich organometallic compounds of middle or late transition metals, including complexes with hydride and phosphine ligands and one with a metal-metal bond. Drawing from a large compilation of gas-phase structures, ${ }^{23}$ we chose complexes for which at least one metal-ligand bond length was determined with a precision better than $1 \mathrm{pm}$, affording a final set of 25 molecules with 41 individual bond distances with that precision, which should be sufficient for reasonable statistics. We also report computed zero-point corrections to the bond distances ${ }^{24,25}$ for this data set in order to furnish increments to estimate $r_{g}{ }^{0}$ from $r_{e}$ values, ${ }^{26}$ thus facilitating the comparison between theory and experiment. 


\section{Computational Details}

Geometries were fully optimized in the given symmetry (as given in Table 1) using Gaussian $03^{27}$ and several local (LSDA) ${ }^{28}$ and gradient-corrected density functional combinations as implemented therein. Most functionals are composed of one of several exchange parts, namely Becke (B) ${ }^{29}$ or Becke hybrid (B3), ${ }^{30}$ together with one of several correlation parts, namely Perdew (P86), ${ }^{31}$ Perdew-Wang (PW91), ${ }^{32}$ or Lee et al. (LYP) ${ }^{33}$ (in parentheses: symbols used in combined forms). Other functionals comprise HCTH/407 (denoted HCTH), ${ }^{34}$ the PBE hybrid functional ${ }^{35}$ (denoted PBE1, Gaussian keyword PBE1PBE, which is often called PBE0), as well as the metaGGAs VSXC ${ }^{36}$ TPSS,${ }^{37}$ and TPSS hybrid (denoted TPSSh). ${ }^{38}$ A fine integration grid (75 radial shells with 302 angular points per shell) has been used, except for VSXC, which has been shown to require finer grids, ${ }^{39}$ and for $\mathrm{WMe}_{6}$, where spurious imaginary frequencies were found with the default grid; in these cases we used 99 radial shells with 590 angular points. The following relativistic small-core ECPs with the corresponding valence basis sets were employed on the metals: $\mathrm{SDD}^{4}$ i.e., the Stuttgart-Dresden ECP (together with the [6s5p3d] valence basis) and LANL2DZ ${ }^{3}$ (with [3s3p2d] valence basis). On the ligands, the $6-31 \mathrm{G}^{*}$ basis ${ }^{40}$ was used, except for $\mathrm{Hf}\left(\mathrm{BH}_{4}\right)_{4}$ and $\mathrm{WCp}_{2} \mathrm{H}_{2}$, where 6-31G** was employed for the ligands with a metal-hydrogen bond. In addition, we tested Ahlrichs-type valence basis sets that had been designed for the use with the SDD ECPs,${ }^{41}$ denoted SVP, TZVP, and QZVP (with [5s3p2d1f], [6s4p3d1f], and [7s5p4d3f1g] contractions for the metals, respectively), together with the corresponding all-electron bases on the ligands. $^{20,21,22}$ The minimum character of all optimized structures was verified by evaluation of the harmonic vibrational frequencies at the BP86/SDD level. Closed- and open-shell species were treated with restricted and unrestricted formalisms, respectively. For the computation of effective geometries via the cubic force field, the Barone method ${ }^{25}$ was invoked at the BP86/SDD level within Gaussian 03 rev D.01. ${ }^{27}$ The default values were used for step size in the numerical differentiation $(0.025 \AA)$ and integration grid (SG1).

Scalar relativistic all electron calculations have been performed with the ORCA program package ${ }^{42}$ within the ZORA approximation. In our experience ZORA and DKH2 geometries are usually almost indistinguishable. For technical reasons, the relativistic corrections have been performed within the one-center approximation that has previously been shown to be adequate. ${ }^{43}$ Geometries have been optimized without constraints due to point symmetry, using the 'pure' GGA and metaGGA functionals (LSDA, BP86, PBE, TPSS), as well as a variety of hybrid functionals (B3LYP, B3P86, B3PW91, TPSSh and PBE1). The integration grid was increased to span 80 radial shells and 302 angular grid points. The influence of the empirical Van der Waals correction according to 
Grimme $^{44}$ has been studied for BP86, PBE, TPSS, and B3LYP. In all ZORA calculations, the recently published SARC basis sets ${ }^{19}$ of TZVP quality has been used for the third-row transition metals, and SARC recontractions of the Karlsruhe TZVP basis set for the lighter atoms. For two molecules $\left(\mathrm{ReOCl}_{4}\right.$ and $\left.\mathrm{IrF}_{6}\right)$, spin-unrestricted open-shell calculations have been performed.

\section{Results and Discussion}

Selection of reference values.

In addition to the precision criterion mentioned in the introduction, we limited our selection to molecules measured at room temperature or slightly above. In some cases, not all degrees of freedom have been refined experimentally, or only mean values for formally non-equivalent distances are known to the desired precision. In those cases, we evaluated and assessed the same average of the corresponding optimized parameters, even though full geometry optimizations were performed. This applies to $\mathrm{Os}(\mathrm{CO})_{5}$ and $\mathrm{WMe}_{6}$. The GED data of the latter were initially refined assuming equal W-C distances; later it was shown that this molecule adopts a structure with lower symmetry and two sets of non-equivalent W-C bonds. ${ }^{53}$ Allowing for fluxional behavior in the gas phase, the refined mean value is probably sufficiently precise. Another such case is $\mathrm{TaCl}_{5}$, where two GED studies ${ }^{48 a, b}$ have reported almost identical mean values of equatorial and axial bonds, but disagree markedly on their difference (which varies between $4.7 \mathrm{pm}^{48 \mathrm{a}}$ and $14.2 \mathrm{pm}^{48 \mathrm{~b}}$ ). It is probably the fluxional behavior of this molecule with its very low Berry pseudo-rotation barrier ${ }^{48 b}$ that makes the actual precision of the individual bond distances somewhat lower than suggested by the quoted standard deviations (which are all well below our target value). Thus, we only discuss the mean $\mathrm{Ta}-\mathrm{Cl}$ distance in this case, as this appears to be refined reasonably well and in a reproducible manner. $\mathrm{Pt}\left(\mathrm{PF}_{3}\right)_{4}$ is also indicated to be fluxional, since the GED data have been found to be consistent with free rotation about the Pt-P bond. ${ }^{64}$ Both staggered and eclipsed conformations turned out to be minima at the BP86(SDD) level, with marginal differences in the optimized bond distances. We employed the slightly more stable eclipsed form ${ }^{45}$ throughout this study.

The final selected experimental parameters are collected in Table 1. Most distances are $r_{\mathrm{a}}$ or $r_{\alpha}$ values determined from GED, and some are $r_{\mathrm{z}}$ or $r_{0}$ geometries are known from MW spectroscopy. In general, when both sets of parameters are known, they tend to be in very good mutual accord, with differences rarely exceeding $1 \mathrm{pm}$, our target precision. 
Table 1: Bond lengths $r$ (in pm) of third-row transition-metal complexes in the gas phase. ${ }^{a}$ Unless otherwise noted, $r_{\mathrm{a}}$ or $r_{\alpha}$ values from GED are given.

\begin{tabular}{|c|c|c|c|c|c|}
\hline \multicolumn{2}{|l|}{ Compound (Mult.) } & \multicolumn{4}{|c|}{ Reference } \\
\hline Sym. & Distance & [bond no.] & value & Ref. & $\Delta r_{\mathrm{vib}}$ \\
\hline $\mathrm{HfCl}_{4}(1) T_{d}$ & $r(\mathrm{Hf}-\mathrm{Cl})$ & {$[1]$} & $231.6(5)$ & 46 & 0.17 \\
\hline \multirow[t]{2}{*}{$\mathrm{Hf}\left(\mathrm{BH}_{4}\right)_{4}(1) T$} & $\mathrm{r}(\mathrm{Hf}-\mathrm{B})$ & {$[2]$} & $231.4(2)$ & 47 & 2.67 \\
\hline & $\mathrm{r}\left(\mathrm{Hf}-\mathrm{H}^{\mathrm{br}}\right)$ & {$[3]$} & $221.5(7)$ & $"$ & 3.27 \\
\hline $\mathrm{TaCl}_{5}(1) D_{3 h}$ & $\mathrm{r}\left(\mathrm{Ta}-\mathrm{Cl}^{\text {mean }}\right)$ & {$[4]$} & $228.5(2)$ & 48 & 0.21 \\
\hline \multirow{2}{*}{$\mathrm{TaMe}_{3} \mathrm{~F}_{2}(1) C_{3 h}$} & $\mathrm{r}(\mathrm{Ta}-\mathrm{C})$ & {$[5]$} & $212.5(5)$ & 49 & 0.20 \\
\hline & $\mathrm{r}(\mathrm{Ta}-\mathrm{F})$ & {$[6]$} & $186.3(4)$ & $"$ & 0.20 \\
\hline $\mathrm{WF}_{6}(1) O_{h}$ & $\mathrm{r}(\mathrm{W}-\mathrm{F})$ & [7] & $182.9(2)$ & 50 & 0.18 \\
\hline \multirow[t]{2}{*}{$\mathrm{WOF}_{4}(1) C_{4 v}$} & $\mathrm{r}(\mathrm{W}=\mathrm{O})$ & {$[8]$} & $166.6(7)$ & 51 & 0.17 \\
\hline & $\mathrm{r}(\mathrm{W}-\mathrm{F})$ & [9] & $184.7(2)$ & $"$ & 0.22 \\
\hline \multirow[t]{2}{*}{$\mathrm{WSCl}_{4}(1) C_{4 v}$} & $\mathrm{r}(\mathrm{W}=\mathrm{S})$ & {$[10]$} & $208.6(6)$ & 52 & 0.17 \\
\hline & $\mathrm{r}(\mathrm{W}-\mathrm{Cl})$ & [11] & $227.7(3)$ & $"$ & 0.27 \\
\hline $\mathrm{WMe}_{6}(1) C_{3}$ & $\mathrm{r}(\mathrm{W}-\mathrm{C})^{\text {mean }}$ & {$[12]$} & $214.6(3)$ & 53 & 0.88 \\
\hline $\mathrm{W}(\mathrm{CO})_{6}(1) O_{h}$ & $\mathrm{r}(\mathrm{W}-\mathrm{C})$ & {$[13]$} & $205.9(3)$ & 54 & 0.40 \\
\hline $\mathrm{W}(\mathrm{Cp})_{2}(\mathrm{H})_{2}(1) C_{2}$ & $\mathrm{r}(\mathrm{W}-\mathrm{H})$ & {$[14]$} & $170.3(2)$ & 55 & 0.86 \\
\hline \multirow[t]{2}{*}{$\operatorname{Re}_{2} \mathrm{~F}_{8}(1) D_{4}$} & $\mathrm{r}(\mathrm{Re}-\mathrm{Re})$ & {$[15]$} & $226.9(5)$ & 56 & 0.27 \\
\hline & $\mathrm{r}(\mathrm{Re}-\mathrm{F})$ & {$[16]$} & $183.0(4)$ & $"$ & 0.20 \\
\hline \multirow[t]{2}{*}{$\mathrm{ReOCl}_{4}(2) C_{4 v}$} & $\mathrm{r}(\mathrm{Re}=\mathrm{O})$ & {$[17]$} & 166.3(9) & 57 & 0.10 \\
\hline & $\mathrm{r}(\mathrm{Re}-\mathrm{Cl})$ & {$[18]$} & $227.0(5)$ & $"$ & 0.28 \\
\hline \multirow[t]{2}{*}{$\mathrm{ReO}_{3} \mathrm{Me}(1) C_{3 v}$} & $\mathrm{r}(\mathrm{Re}=\mathrm{O})$ & [19] & $170.9(3)$ & 58 & 0.21 \\
\hline & $\mathrm{r}(\mathrm{Re}-\mathrm{C})$ & {$[20]$} & 206.0(9) & $"$ & 0.41 \\
\hline \multirow[t]{4}{*}{$\mathrm{ReO}_{2} \mathrm{Me}\left(\mathrm{C}_{2} \mathrm{H}_{2}\right)(1) C_{s}$} & $\mathrm{r}(\mathrm{Re}=\mathrm{O})$ & {$[21]$} & 171.0(1) & 59 & 0.15 \\
\hline & $\mathrm{r}\left(\mathrm{Re}-\mathrm{C}^{\mathrm{Me}}\right)$ & {$[22]$} & $211.6(2)$ & $"$ & 0.60 \\
\hline & $\mathrm{r}\left(\mathrm{Re}-\mathrm{C}^{1}\right)$ & {$[23]$} & $204.3(2)$ & $"$ & 0.54 \\
\hline & $r\left(\operatorname{Re}-C^{2}\right)$ & {$[24]$} & $206.7(2)$ & $"$ & 0.72 \\
\hline $\mathrm{OsO}_{4}(1) T_{d}$ & $\mathrm{r}(\mathrm{Os}=\mathrm{O})$ & {$[25]$} & $171.2(2)$ & 60 & 0.27 \\
\hline \multirow[t]{2}{*}{$\mathrm{OsOCl}_{4}(1) C_{4 v}$} & $\mathrm{r}(\mathrm{Os}=\mathrm{O})$ & [26] & $166.3(9)$ & 61 & 0.11 \\
\hline & $\mathrm{r}(\mathrm{Os}-\mathrm{Cl})$ & {$[27]$} & $225.8(5)$ & $"$ & 0.33 \\
\hline $\mathrm{Os}(\mathrm{CO})_{5}(1) D_{3 h}$ & $\mathrm{r}(\mathrm{Os}-\mathrm{C})^{\text {mean }}$ & {$[28]$} & $196.2(4)$ & 62 & 0.33 \\
\hline \multirow[t]{3}{*}{$\mathrm{Os}\left(\mathrm{C}_{2} \mathrm{H}_{4}\right)(\mathrm{CO})_{4}(1) C_{2 v}$} & $\mathrm{r}\left(\mathrm{Os}-\mathrm{C}^{\mathrm{et}}\right)$ & [29] & $220.9(5)$ & 63 & 0.86 \\
\hline & $\mathrm{r}\left(\mathrm{Os}-\mathrm{C}^{\mathrm{ax}}\right)$ & {$[30]$} & $195.4(2)$ & $"$ & 0.38 \\
\hline & $\mathrm{r}\left(\mathrm{Os}-\mathrm{C}^{\mathrm{eq}}\right)$ & {$[31]$} & $194.6(5)$ & $"$ & 0.31 \\
\hline $\mathrm{IrF}_{6}(4) O_{h}$ & $\mathrm{r}(\mathrm{Ir}-\mathrm{F})$ & {$[32]$} & $183.9(2)$ & 50 & 0.31 \\
\hline $\operatorname{Pt}\left(\mathrm{PF}_{3}\right)_{4}(1) T_{d}$ & $\mathrm{r}(\mathrm{Pt}-\mathrm{P})$ & {$[33]$} & $222.9(5)$ & 64 & 0.53 \\
\hline \multirow[t]{2}{*}{$\mathrm{Au}(\mathrm{CO}) \mathrm{Cl}(1) C_{\infty v}$} & $\mathrm{r}(\mathrm{Au}-\mathrm{Cl})$ & {$[34]$} & $221.72(6)$ & 65 & 0.36 \\
\hline & $\mathrm{r}(\mathrm{Au}-\mathrm{C})$ & {$[35]$} & $188.4(2)$ & $"$ & 0.48 \\
\hline $\mathrm{Au}(\mathrm{Me})\left(\mathrm{PMe}_{3}\right)(1) C_{3}$ & $\mathrm{r}(\mathrm{Au}-\mathrm{P})$ & {$[36]$} & $228.0(5)$ & 66 & 0.32 \\
\hline
\end{tabular}




\begin{tabular}{lllrrr}
$\mathrm{Hg}(\mathrm{Me}) \mathrm{Cl}(1) C_{3 v}$ & $\mathrm{r}(\mathrm{Hg}-\mathrm{Cl})$ & {$[37]$} & $228.5(3)$ & 67 & 0.35 \\
& $\mathrm{r}(\mathrm{Hg}-\mathrm{C})$ & {$[38]$} & $205.2(5)$ & $"$ & 0.49 \\
$\mathrm{Hg}\left(\mathrm{CF}_{3}\right)_{2}(1) D_{3}$ & $\mathrm{r}(\mathrm{Hg}-\mathrm{C})$ & {$[39]$} & $210.6(5)$ & 68 & 0.40 \\
$\mathrm{Hg}(\mathrm{Me})(\mathrm{CN})(1) C_{3 v}$ & $\mathrm{r}\left(\mathrm{Hg}-\mathrm{C}^{\mathrm{CN}}\right)$ & {$[40]$} & $203.69(2)$ & 69 & 0.39 \\
& $\mathrm{r}\left(\mathrm{Hg}-\mathrm{C}^{\mathrm{Me}}\right)$ & {$[41]$} & $205.63(1)$ & $"$ & 0.43 \\
\hline
\end{tabular}

(in parentheses: multiplicity) ax = axial, br = bridging, $\mathrm{Cp}=$ cyclopentadienyl; eq $=$ equatorial. et $=$ ethylene.

Table 2. Statistical assessment of equilibrium $\left(r_{\mathrm{e}}\right)$ and effective $\left(r_{\mathrm{eff}}\right)$ metal-ligand bond distances computed for the test set in Scheme 1 at a number of levels of theory. All values are in picometers relative to experimentally reported values $\left(r_{\text {exp }}\right){ }^{a}$

\begin{tabular}{|c|c|c|c|c|c|c|c|c|}
\hline Entry & Functional & $\begin{array}{c}\mathrm{ECP} / \\
\text { Basis Set }^{b}\end{array}$ & $\bar{D}^{\text {equil }}$ & $\left|\bar{D}^{\text {equil }}\right|$ & $\bar{D}_{\text {std }}^{\text {equil c }}$ & $D_{\max }^{\text {equil }}$ & $\bar{D}^{e f f}$ & $\bar{D}_{s t d}^{e f f}$ \\
\hline 1 & LSDA & SDD & -0.26 & 1.56 & $2.10(1.46)$ & $-8.7[3]$ & 0.23 & 1.70 \\
\hline 2 & PBE1 & SDD & 1.07 & 1.67 & $2.07(1.58)$ & $5.8[36]$ & 1.56 & 1.76 \\
\hline 3 & B3P86 & SDD & 1.32 & 1.83 & $2.09(1.53)$ & $-7.7[3]$ & 1.81 & 1.75 \\
\hline 4 & B3PW91 & SDD & 1.64 & 2.05 & $2.11(1.60)$ & $-7.1[3]$ & 2.13 & 1.80 \\
\hline 5 & TPSSh & SDD & 2.24 & 2.66 & $2.25(1.53)$ & $-8.2[3]$ & 2.72 & 1.88 \\
\hline 6 & PBE & SDD & 2.76 & 3.06 & 2.17 (1.69) & 6.9 [36] & 3.25 & 1.82 \\
\hline 7 & B3LYP & SDD & 2.92 & 3.22 & $2.43(1.97)$ & $9.6[36]$ & 3.41 & 2.18 \\
\hline 8 & TPSS & SDD & 2.94 & 3.33 & $2.33(1.59)$ & $-7.8[3]$ & 3.43 & 1.94 \\
\hline 9 & BPW91 & SDD & 3.05 & 3.34 & $2.24(1.74)$ & $7.6[36]$ & 3.54 & 1.90 \\
\hline 10 & BP86 & SDD & 3.10 & 3.39 & $2.21(1.69)$ & $7.5[36]$ & 3.59 & 1.87 \\
\hline 11 & VSXC & SDD & 3.23 & 3.56 & $2.51(1.95)$ & 9.4 [36] & 3.72 & 2.22 \\
\hline 12 & BLYP & SDD & 4.78 & 5.01 & $2.63(2.19)$ & $11.6[36]$ & 5.27 & 2.37 \\
\hline 13 & BP86 & LANL2DZ & 3.94 & 4.50 & $6.09(5.87)$ & $21.0[39]$ & 4.43 & 5.94 \\
\hline 14 & BP86 & $\mathrm{LANL}_{2} \mathrm{DZ}^{d}$ & 5.82 & 6.33 & $6.56(6.39)$ & 21.3 [37] & 6.31 & 6.40 \\
\hline 15 & BP86 & $\mathrm{SDD} / \mathrm{SVP}^{e}$ & 2.78 & 3.06 & $2.17(1.71)$ & 8.0 [36] & 3.27 & 1.90 \\
\hline 16 & BP86 & $\mathrm{SDD} / \mathrm{TZVP}{ }^{e}$ & 2.33 & 2.67 & $2.21(1.68)$ & $-6.7[3]$ & 2.82 & 1.91 \\
\hline 17 & BP86 & $\mathrm{SDD} / \mathrm{QZVP}{ }^{e}$ & 1.89 & 2.22 & $1.94(1.37)$ & $-6.8[3]$ & 2.37 & 1.63 \\
\hline 18 & B3P86 & $\mathrm{SDD} / \mathrm{SVP}^{e}$ & 0.97 & 1.85 & $2.23(1.79)$ & $-7.5[3]$ & 1.46 & 2.00 \\
\hline 19 & B3P86 & $\mathrm{SDD} / \mathrm{TZVP}{ }^{e}$ & 0.49 & 1.56 & $2.15(1.63)$ & $-8.4[3]$ & 0.97 & 1.88 \\
\hline 20 & PBE1/ & $\mathrm{SDD} / \mathrm{SVP}^{e}$ & 0.69 & 1.74 & $2.23(1.85)$ & $-7.3[3]$ & 1.18 & 2.02 \\
\hline 21 & PBE1 & $\mathrm{SDD} / \mathrm{TZVP} \mathrm{P}^{e}$ & 0.18 & 1.48 & $2.12(1.66)$ & $-8.2[3]$ & 0.67 & 1.87 \\
\hline 22 & PBE1 & $\mathrm{SDD} / \mathrm{QZVP}{ }^{e}$ & -0.23 & 1.26 & $1.90(1.42)$ & $-8.3[3]$ & 0.26 & 1.66 \\
\hline 23 & LSDA & SDD/QZVP & -1.49 & 1.77 & $1.93(1.45)$ & $-9.9[3]$ & -0.99 & 1.56 \\
\hline 24 & LSDA & ZORA/TZVP & -1.82 & 2.01 & $2.30(1.66)$ & $-11.9[3]$ & -1.34 & .87 \\
\hline
\end{tabular}




\begin{tabular}{lllllllll}
25 & PBE1 & ZORA/TZVP & -0.50 & 1.53 & $2.21(1.66)$ & $-9.7[3]$ & -0.02 & 1.90 \\
26 & B3P86 & ZORA/TZVP & 0.04 & 1.60 & $2.28(1.69)$ & $-9.6[3]$ & 0.53 & 1.96 \\
27 & B3PW91 & ZORA/TZVP & 0.07 & 1.63 & $2.27(1.71)$ & $-9.4[3]$ & 0.56 & 1.97 \\
28 & TPSSh & ZORA/TZVP & 0.56 & 1.72 & $2.45(1.67)$ & $-10.7[3]$ & 1.05 & 2.08 \\
29 & PBE & ZORA/TZVP & 1.26 & 2.08 & $2.32(1.74)$ & $-8.5[3]$ & 1.75 & 1.97 \\
30 & B3LYP & ZORA/TZVP & 1.50 & 2.29 & $2.60(2.09)$ & $-8.3[3]$ & 1.99 & 2.34 \\
31 & TPSS & ZORA/TZVP & 1.29 & 2.08 & $2.52(1.70)$ & $-10.4[3]$ & 1.78 & 2.13 \\
32 & BPW91 & ZORA/TZVP & 1.52 & 2.22 & $2.38(1.80)$ & $-8.4[3]$ & 2.01 & 2.04 \\
33 & BP86 & ZORA/TZVP & 1.50 & 2.20 & $2.39(1.78)$ & $-8.6[3]$ & 1.99 & 2.04 \\
34 & BLYP & ZORA/TZVP & 3.45 & 3.79 & $2.79(2.27)$ & $9.1[36]$ & 3.93 & 2.52 \\
35 & PBE+VdW & ZORA/TZVP & 1.14 & 2.12 & $2.49(1.82)$ & $-9.6[3]$ & 1.63 & 2.09 \\
36 & B3LYP+VdW & ZORA/TZVP & 1.34 & 2.31 & $2.78(2.15)$ & $-9.9[3]$ & 1.83 & 2.47 \\
37 & TPSS+VdW & ZORA/TZVP & 1.12 & 2.10 & $2.74(1.80)$ & $-11.9[3]$ & 1.61 & 2.31 \\
38 & BP86+VdW & ZORA/TZVP & 1.32 & 2.23 & $2.61(1.87)$ & $-10.2[3]$ & 1.81 & 2.20 \\
39 & BLYP+VdW & ZORA/TZVP & 3.25 & 3.77 & $3.03(2.38)$ & $8.8[36]$ & 3.73 & 2.69 \\
\hline
\end{tabular}

${ }^{a} \bar{D}^{\text {equil }}, \overline{D D}^{\text {equil }}, \bar{D}_{\text {std }}^{\text {equil }}$ and $D_{\max }^{\text {equil }}$ denote mean, mean absolute, standard, and maximum absolute deviations, respectively, for the equilibrium geometries, $\bar{D}^{\text {eff }}$ and $\bar{D}_{\text {std }}^{\text {eff }}$ the corresponding deviations for the zero-point averaged, effective geometries. In square brackets: bond numbers from Table 1 for which the maximum error occurs. ${ }^{b} 6-31 G^{*}$ basis for the ligands, except where otherwise noted. ${ }^{c}$ in parentheses: standard deviations for geometries excluding bond no. 3 (see text). ${ }^{d} \mathrm{D} 95$ for the ligands. ${ }^{e}$ The corresponding Ahlrichs basis sets are used on the ligands.

\section{Performance of the ECP models.}

Individual distances optimized with the various density-functional/ECP/basis-set combinations are given as Supporting Information (SI). The resulting statistical assessment, that is, the mean and standard deviations from the reference data in Table 1 , are summarized in Table $2\left(\bar{D}^{\text {equil }}\right.$ and $\bar{D}_{\text {std }}^{\text {equil }}$ values, respectively). Deviations are defined as $r_{\text {calc }}-r_{\exp }$, such that positive mean deviations denote overestimation of the bond lengths by DFT. In addition, the mean absolute and the maximum errors to either side are included in Table 2 (labelled $|\bar{D}|^{\text {equil }}$ and $D_{\max }^{\text {equil }}$, respectively). It turned out that, in particular, the standard deviation is strongly influenced by a single outlier, namely the $\mathrm{Hf}-\mathrm{H}^{\text {br }}$ bond in $\mathrm{Hf}\left(\mathrm{BH}_{4}\right)_{4}$ (bond no. [3]), which is significantly underestimated at all DFT levels. ${ }^{70}$ In order to 
assess the effect of this bond on the overall statistics, we also provide $\bar{D}_{\text {std }}^{\text {equil }}$ values where this bond has been removed from the data set (values in parentheses in Table 2).

First, all functionals were tested with the SDD ECP and valence basis on the metal and 6-31G* basis on the ligands (entries 1 - 12 in Table 2, arranged in the order of increasing mean deviation). Next, another ECP and/or other basis sets were employed for selected functionals, notably BP86 (for comparison with the results for the first and second transition rows), B3P86 and PBE1.

Following the procedure of our previous studies, effective geometries were then computed at the BP86/SDD level, via numerical computation of the cubic force field using the method of Barone et al. This affords incremental corrections to the bond distances, $\Delta r_{\text {vib }}$ (given in the last column of Table 1), leading from the equilibrium values $r_{e}$ to the zero-point averaged ones, $r_{g}{ }^{0}$. Arguably, the latter are better suited for direct comparison to the experimental, thermally averaged distances than the former. Actually, there is evidence for small first-row molecules that the zero-point motion affords the largest correction to equilibrium distances, and that thermal effects on top of them (i.e. the difference between zero and finite $\mathrm{T}$ ) tend to be much smaller. ${ }^{71}$ If this holds also for the transition-metal complexes, the effective or $r_{g}{ }^{0}$ geometries should be a quite good approximation to the experimental $r_{\mathrm{a}}$ or $r_{0}$ structures.

Assuming the same extent of transferability between computational levels that has been established in our studies of 3d- and 4d-metal complexes, we have added the $\Delta r_{\text {vib }}$ values evaluated at the BP86/SDD level to the corresponding equilibrium distances obtained at all other levels and repeated the statistical analysis with respect to the experimental reference data. The corresponding mean and absolute deviations are included in the last two columns in Table 2, labelled $\bar{D}^{\text {eff }}$ and $\bar{D}_{\text {std }}^{\text {eff }}$. The former, mean error is shifted with respect to that of the equilibrium distances, $\bar{D}^{\text {equil }}$, by a constant amount of ca. $+0.5 \mathrm{pm}$. This is because all individual increments (last column in Table 1) are positive, i.e. bonds get longer upon zero-point averaging. The individual increments themselves are quite variable, however, ranging from very small changes for metal-oxo multiple bonds (ca. 0.1 $\mathrm{pm}$ ), via intermediate values for metal-carbon bonds (up to ca. $0.9 \mathrm{pm}$ ), to quite large values for the bonds involving the boranate ligand in $\mathrm{Hf}\left(\mathrm{BH}_{4}\right)_{4}$, where the corrections amount to more than $3 \mathrm{pm}$ for the Hf-H distance (see Table 1). Since this distance appears to be significantly underestimated in most equilibrium geometries (see SI and $D_{\max }^{\text {equil }}$ values in Table 2), ${ }^{70}$ the vibrational correction 
significantly reduces the error for this bond, thereby leading to noticeable improvements in the standard deviations (compare $\bar{D}_{\text {std }}^{\text {equil }}$ and $\bar{D}_{\text {std }}^{\text {eff }}$ values in Table 2).

The following conclusions can be drawn from our results for the 5d-metal complexes:

- In conjunction with SDD and 6-31G* basis, LSDA outperforms all other functionals. It has the smallest mean deviation close to zero for both equilibrium and effective geometries, and one of the smallest standard deviations (entry 1 in Table 2). This observation is in marked contrast to the firstand second-row transition-metal complexes, where the tendency of LSDA to overbind translates into optimized (or effective) distances that are much too short.

- Hybrid functionals are consistently superior to GGAs and meta-GGAs, except for B3LYP, which is surpassed by PBE, and more or less matched by a number of other standard GGAs such as BPW91 or BP86. The two most promising hybrid functionals are PBE1 and B3P86.

- BLYP and the meta-GGA VSXC produce some of the largest mean and standard deviations, and cannot be recommended, consistent with our findings for the lighter metal complexes.

- The LANL2DZ ECPs together with their compact valence bases are inferior to the corresponding SDD variants with their more flexible basis sets. The large errors evident from Table 2 for LANL2DZ (entry 13) are to a large extent due to some spectacular failures for the linear $\mathrm{Hg}$ (II) species in the set (see SI and $D_{\max }^{\text {equil }}$ values in Table 2). ${ }^{72}$ For the other complexes, the relative performance of LANL2DZ and SDD is less disparate, but the latter is, in general, slightly superior (arguably due to the more flexible valence basis on the metal). ${ }^{73}$

- Larger basis sets are beneficial. In particular in the Ahlrichs series, the systematic increase of the metal-valence and ligand bases from SVP to TZVP and QZVP is concomitant with a decrease in mean and standard deviations (e.g. with the PBE1 functional, entries 20-22 in Table 2). For LSDA, such a basis-set extension worsens the agreement with experiment somewhat (compare entries 1 and 23 in Table 2), but also at the LSDA/SDD/QZVP level, a very respectable mean error (below $1 \mathrm{pm}$ for $\bar{D}^{\text {eff }}$ ) and one of the lowest standard deviations remain. 
The good performance of LSDA for the 5d complexes is noteworthy. The tendency to underestimate metal-ligand bond lengths at that level is most pronounced in the first transition row, ${ }^{7}$ somewhat alleviated but still noticeable in the second, ${ }^{8}$ and all but disappeared in the third. This trend seen in the whole sets is also found in individual homologous compounds that are present in all sets, namely the group- 4 tetrachlorides and group- 8 pentacarbonyls (see selected data in Table S4 in the Supporting Information). For main-group compounds, the ubiquitous overbinding of LSDA does not appear to result in such a pronounced underestimation of bond lengths as found for the $3 \mathrm{~d}-$ metals (see reference 74 and some illustrative data in Table S5 of the SI).
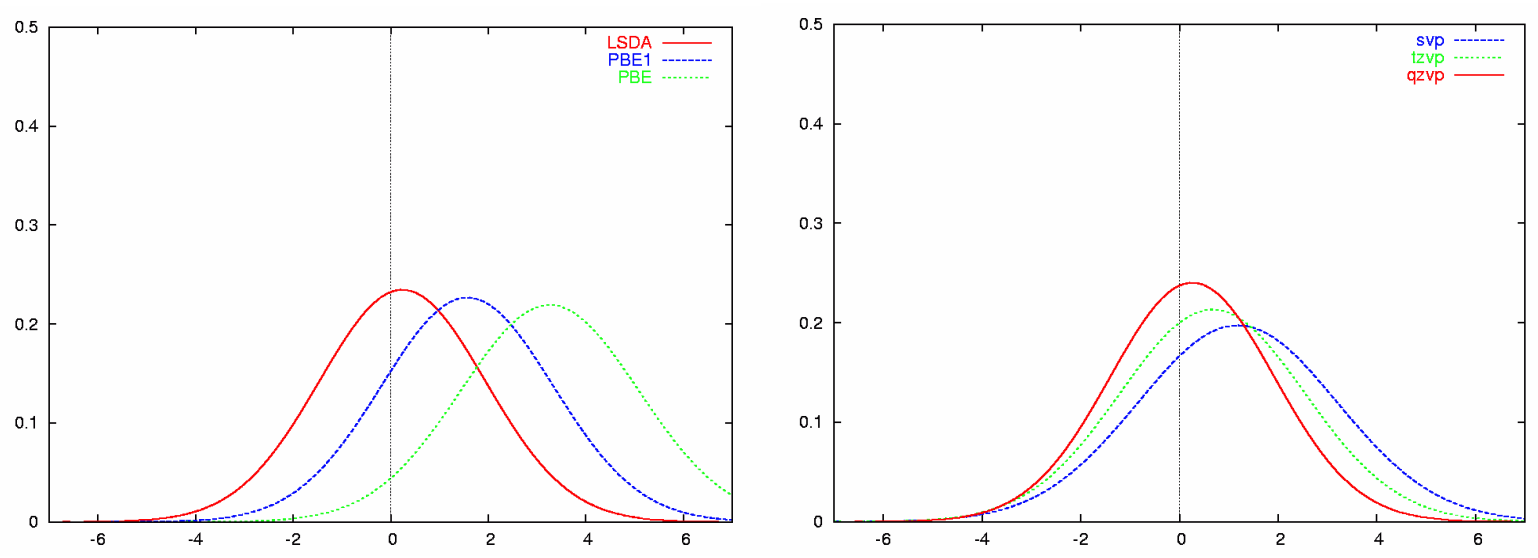

Figure 1: Normal distributions for the errors in the effective bond distances for the test set in Scheme 1. The distributions have been calculated from the mean and standard deviations in Table 2 and are all normalized to one. (a) left: dependence on the density functional using SDD ECP and valence basis (6-31G* on the ligands); (b) right: dependence on the basis set for the PBE1 hybrid functional together with the SDD ECP.

To conclude this section, LSDA and most hybrid functionals are quite robust in reproducing geometries of third-row transition metal complexes, and tend to be more accurate than pure or metaGGAs. Except from LSDA, PBE1 affords the lowest mean deviation, and one of the lowest standard deviations, 1.6 and $1.8 \mathrm{pm}$, respectively, at the SDD level (which are further improved with the larger tzvp and qzvp basis sets). The best GGA is PBE, slightly superior to B3LYP. The performance of these three functionals is shown schematically in Figure 1a, a plot of normalized Gaussian distributions using the corresponding data from Table 2 (analogous to the presentation by Helgaker et al). ${ }^{5,6}$ Figure $1 \mathrm{~b}$ illustrates the basis-set dependence for one particular density functional, PBE1, where increase of the basis results in noticeable shifts of the normal distribution, and some reduction of its width for the largest basis, qzvp. The provisional ranking of the functionals for the 5d-metal complexes, ordered according to increasing mean deviation at the SDD level, is thus the following: 
LSDA $<$ PBE $1 \approx$ B3P86 $\approx$ B3PW91 $<$ TPSSh $<$ PBE $\approx$ B3LYP $\approx$ TPSS $\approx$ BPW91 $\approx$ BP86 $<$ VSXC $<$ BLYP

\section{Performance of the all-electron models.}

The scalar relativistic results generally show slightly smaller mean deviations than their ECP counterparts (except for LSDA), but the corresponding standard deviations always slightly exceed those of the SDD ECP results. However, for all intents and purposes, the results are very similar since the difference in the standard deviations is merely $0.17 \mathrm{pm}$ on average for all methods. The standard deviation is significantly reduced when the $\mathrm{Hf}-\mathrm{H}^{\mathrm{br}}$ bond distance (bond no. 3 ) is discarded as an outlier (see Table 2, values in parentheses, and the discussion above). The errors for the zeropoint averaged effective geometries follow the same trend as described above for the ECP case.

The ranking of the functionals is slightly changed in the all-electron calculations since the LSDA functional now shows the largest mean deviation thus indicating a systematic underestimation of bond distances. However, its standard deviation is still quite small. Consistent with the ECP results, the hybrid functionals B3P86, B3PW91, PBE1 and TPSSh provide the most accurate results, while the performance of B3LYP and BLYP is considerably worse. In fact, B3LYP and BLYP exhibit the largest standard deviations in this set. The GGA and meta-GGA functionals are found to give similar results, with PBE again being superior to TPSS, BP86 and BPW91. The inclusion of the empirical Van der Waals (VdW) corrections does not lead to noticeable improvements in the results in this test set (compare for instance, entries 29 and 35 in Table 2). We have, however, frequently found significantly improved geometries in sterically crowded systems and stacked pi-systems with this correction. Upon adding the zero-point average, the standard deviations are further improved, again in agreement with the ECP results.

\section{Performance of the models for all transition rows}

Combining the present results on the third-row metals with those from our previous studies on firstand second-row metals affords a comprehensive validation for the whole d-block. A selection of levels that are available for all sets ${ }^{75}$ are assessed in Table 3. For the first and second transition row, additional scalar relativistic ZORA calculations have been performed according to the approach described above, in order to allow for a fair comparison. 
Table 3. Statistical assessment of equilibrium $\left(r_{\mathrm{e}}\right)$ and effective $\left(r_{\text {eff }}\right)^{76}$ metal-ligand bond distances computed for the combined test sets of all $3 \mathrm{~d}, 4 \mathrm{~d}$, and $5 \mathrm{~d}$ metal complexes at selected levels of theory. All values are in picometers relative to experimentally reported values $\left(r_{\text {exp }}\right){ }^{a}$

\begin{tabular}{|c|c|c|c|c|c|c|c|c|}
\hline Entry & Functional & $\begin{array}{c}3 \mathrm{~d} \text { ECP/ } \\
\text { Basis set }^{b}\end{array}$ & $\begin{array}{l}\text { 4d,5d ECP } \\
/ \text { Basis Set }^{b}\end{array}$ & $\bar{D}^{\text {equil }}$ & $\bar{D}_{s t d}^{\text {equil }}$ & $D_{\max }^{\text {equil }} c$ & $\bar{D}^{e f f}$ & $\bar{D}_{s t d}^{e f f}$ \\
\hline 1 & BP86 & SDD & SDD & 1.40 & 2.63 & 7.5 [5d:36] & 1.94 & 2.56 \\
\hline 2 & BP86 & AE1 & SDD & 1.80 & 2.32 & $7.5[5 \mathrm{~d}: 36]$ & 2.34 & 2.22 \\
\hline 3 & В3Р86 & AE1 & SDD & 0.04 & 2.10 & $-7.7[5 \mathrm{~d}: 3]$ & 0.57 & 2.02 \\
\hline 4 & BLYP & AE1 & SDD & 3.71 & 2.61 & $11.6[5 \mathrm{~d}: 36]$ & 4.25 & 2.58 \\
\hline 5 & B3LYP & AE1 & SDD & 1.85 & 2.35 & 9.6 [5d:36] & 2.39 & 2.35 \\
\hline 6 & B3LYP & SDD & SDD & 1.43 & 2.68 & 9.6 [5d:36] & 1.97 & 2.69 \\
\hline 7 & BPW91 & AE1 & SDD & 1.78 & 2.31 & 7.6 [5d:36] & 2.32 & 2.20 \\
\hline 8 & B3PW91 & AE1 & SDD & 0.39 & 2.12 & $-7.1[5 \mathrm{~d}: 3]$ & 0.93 & 2.05 \\
\hline 9 & TPSS & AE1 & SDD & 1.59 & 2.27 & -7.8 [5d:3] & 2.12 & 2.11 \\
\hline 10 & TPSSh & AE1 & SDD & 0.91 & 2.18 & $-8.2[5 \mathrm{~d}: 3]$ & 1.44 & 2.05 \\
\hline 11 & LSDA & AE1 & SDD & -2.01 & 2.71 & $-8.7[5 \mathrm{~d}: 3]$ & -1.47 & 2.54 \\
\hline 12 & VSXC & AE1 & SDD & 2.56 & 2.48 & 16.9 [4d:28] & 3.10 & 2.48 \\
\hline 13 & PBE1 & AE1 & SDD & -0.17 & 2.14 & $-7.4[5 \mathrm{~d}: 3]$ & 0.37 & 2.08 \\
\hline 14 & BP86 & svp & $\mathrm{SDD}_{/ \mathrm{SVP}}{ }^{d}$ & 1.16 & 2.40 & $8.0[5 \mathrm{~d}: 36]$ & 1.70 & 2.36 \\
\hline 15 & BP86 & tzvp & $\mathrm{SDD} / \mathrm{TZVP}^{d}$ & 1.39 & 2.19 & $-6.7[5 \mathrm{~d}: 3]$ & 1.92 & 2.12 \\
\hline 16 & BP86 & qzvp & $\mathrm{SDD} / \mathrm{QZVP}{ }^{d}$ & 0.93 & 1.99 & $-6.8[5 \mathrm{~d}: 3]$ & 1.47 & 1.93 \\
\hline 17 & BP86 & TZVP & ZORA/TZVP & 1.24 & 2.29 & $-8.6[5 \mathrm{~d}: 3]$ & 1.78 & 2.18 \\
\hline 18 & TPSS & TZVP & ZORA/TZVP & 1.04 & 2.19 & $-10.4[5 \mathrm{~d}: 3]$ & 1.58 & 2.02 \\
\hline 19 & TPSSh & TZVP & ZORA/TZVP & 0.31 & 2.07 & $-10.7[5 \mathrm{~d}: 3]$ & 0.84 & 1.92 \\
\hline 20 & PBE & TZVP & ZORA/TZVP & 0.99 & 2.25 & $-8.5[5 \mathrm{~d}: 3]$ & 1.53 & 2.13 \\
\hline 21 & PBE1 & TZVP & ZORA/TZVP & -0.79 & 2.00 & $-9.7[5 \mathrm{~d}: 3]$ & -0.25 & 1.93 \\
\hline 22 & $\mathrm{PBE}+\mathrm{VdW}$ & TZVP & ZORA/TZVP & 0.87 & 2.40 & $-9.6[5 d: 3]$ & 1.41 & 2.24 \\
\hline 23 & LSDA & ZORA/TZVP & ZORA/TZVP & -2.63 & 2.65 & $-11.9[5 \mathrm{~d}: 3]$ & -2.09 & 2.46 \\
\hline 24 & PBE1 & ZORA/TZVP & ZORA/TZVP & -1.05 & 2.11 & $-9.7[5 \mathrm{~d}: 3]$ & -0.51 & 2.04 \\
\hline 25 & B3P86 & ZORA/TZVP & ZORA/TZVP & -0.48 & 2.19 & $-9.6[5 \mathrm{~d}: 3]$ & 0.06 & 2.12 \\
\hline 26 & B3PW91 & ZORA/TZVP & ZORA/TZVP & -0.46 & 2.18 & -9.4 [5d:3] & 0.08 & 2.11 \\
\hline 27 & TPSSh & ZORA/TZVP & ZORA/TZVP & 0.04 & 2.23 & $-10.7[5 \mathrm{~d}: 3]$ & 0.58 & 2.09 \\
\hline 28 & PBE & ZORA/TZVP & ZORA/TZVP & 0.73 & 2.43 & $-8.5[5 \mathrm{~d}: 3]$ & 1.26 & 2.32 \\
\hline 29 & B3LYP & ZORA/TZVP & ZORA/TZVP & 1.17 & 2.50 & $-8.3[5 \mathrm{~d}: 3]$ & 1.70 & 2.50 \\
\hline 30 & TPSS & ZORA/TZVP & ZORA/TZVP & 0.77 & 2.38 & $-10.4[5 \mathrm{~d}: 3]$ & 1.30 & 2.22 \\
\hline 31 & BPW91 & ZORA/TZVP & ZORA/TZVP & 1.00 & 2.46 & $-8.4[5 \mathrm{~d}: 3]$ & 1.54 & 2.36 \\
\hline 32 & BP86 & ZORA/TZVP & ZORA/TZVP & 0.98 & 2.47 & $-8.6[5 \mathrm{~d}: 3]$ & 1.52 & 2.38 \\
\hline
\end{tabular}




\begin{tabular}{|c|c|c|c|c|c|c|c|c|}
\hline 33 & BLYP & ZORA/TZVP & ZORA/TZVP & 3.11 & 2.86 & $9.1[5 \mathrm{~d}: 36]$ & 3.65 & 2.83 \\
\hline 34 & $\mathrm{PBE}+\mathrm{VdW}$ & ZORA/TZVP & ZORA/TZVP & 0.62 & 2.56 & $-9.6[5 \mathrm{~d}: 3]$ & 1.16 & 2.41 \\
\hline 35 & $\mathrm{~B} 3 \mathrm{LYP}+\mathrm{VdW}$ & ZORA/TZVP & ZORA/TZVP & 0.92 & 2.48 & $-9.9[5 \mathrm{~d}: 3]$ & 1.45 & 2.40 \\
\hline 36 & TPSS+VdW & ZORA/TZVP & ZORA/TZVP & 0.54 & 2.53 & -11.9 [5d:3] & 1.08 & 2.31 \\
\hline 37 & BP86+VdW & ZORA/TZVP & ZORA/TZVP & 0.83 & 2.61 & $-10.2[5 \mathrm{~d}: 3]$ & 1.36 & 2.47 \\
\hline 38 & $\mathrm{BLYP}+\mathrm{VdW}$ & ZORA/TZVP & ZORA/TZVP & 2.78 & 2.83 & 8.8 [4d:28] & 3.32 & 2.73 \\
\hline
\end{tabular}

from references 7,8 , and this work.

Unexpectedly, the standard deviations are somewhat smaller in the all-electron calculations when the 3d-complexes are calculated without relativistic corrections, while the mean errors are superior only for PBE (with and without Van der Waals contributions) and PBE1. The effect of the relativistic corrections is to decrease the metal-ligand bond distances. According to our experience the nonrelativistic all-electron calculated DFT distances are slightly overestimated in many Werner type complexes. ${ }^{77}$ Hence the scalar relativistic effects will often provide a correction in the right direction. However, for the present set of $3 d$ transition metal complexes this seems not to be the case. By comparing the AE1(3d)/SDD $(4 d+5 d)$ to TZVP(3d)/ZORA+TZVP $(4 d+5 d)$ results in Table 3 for the functionals BP86, TPSS, TPSSh and PBE1, the errors are slightly reduced, with the mean deviation of PBE1 being the only exception. For BP86, more combinations of methods and basis sets have been evaluated than for the other functionals. Using ECPs for $3 \mathrm{~d}, 4 \mathrm{~d}$ and $5 \mathrm{~d}$ molecules give the largest errors while a scalar relativistic treatment throughout all 3 rows gives the lowest error, but still a rather large standard deviation. The combination $A E 1(3 d) / S D D+t z v p(4 d+5 d)$ gives the best standard deviation, while the mean error is slightly larger than the one for the combination $\operatorname{TZVP}(3 \mathrm{~d}) / Z O R A+T Z V P(4 d+5 d)$.

Because most functionals show subtle differences in performance for the various transition rows (e.g. TPSS is very good for $3 \mathrm{~d}$ complexes, but lags behind for the heavier congeners), the overall performance of the functionals tends to even out over the whole d-block. BLYP and VSXC show large mean and standard deviations throughout, and for LSDA, the good performance in the ECP calculations for the $5 \mathrm{~d}$ row cannot make up for the deficiencies apparent for the $3 \mathrm{~d}$ and $4 \mathrm{~d}$ series. Overall the latter three functionals are trailing behind the others and cannot be recommended for geometry optimizations of transition-metal complexes. Most of the other functionals form a sort of peloton, for which it is difficult to single out clear leaders. The slight superiority of B3P86 and PBE1 noted in the $4 \mathrm{~d}$ and $5 \mathrm{~d}$ complexes is preserved for the whole set, however. Thus, these 
functionals emerge as being quite robust for the computation of geometries of transition-metal complexes in general.

However, while these functionals do show low mean deviations from experiment (between ca. 0.4 pm - 0.6 pm, $\bar{D}^{\text {eff }}$ values in Table 3), and have the lowest associated standard deviations of ca. 2 pm (see $\bar{D}_{\text {std }}^{\text {equil }}$ or $\bar{D}_{\text {std }}^{\text {eff }}$ values in Table 3 ), the latter values imply a notable scatter of the computed bond distances about the experimental values. For comparison, the accuracy achievable with highly sophisticated ab initio methods for equilibrium bond distances of light main-group compounds is much better (cf. mean and standard deviation around 0.2 and $0.3 \mathrm{pm}$, respectively, at CCSD(T)/ccpVQZ). ${ }^{5,6}$ In this context it should be kept in mind that even reasonably precise GED results for transition metal complexes, which form a major source of the experimental database used in our analyses, need not necessarily be highly accurate. If any decomposition reactions during vaporization of the samples go undetected, the observed radial distributions and, thus, the structural parameters derived thereof may be affected noticeably. Thus, the high accuracy achievable for light main-group compounds appears to be out of reach, or at least undetectable, for transition metal complexes. Nevertheless, there appears to be room of improvement for the development of new exchange-correlation functionals for the description of transition-metal complexes.

\section{Conclusions}

This work concludes our extended validation study of DFT methods for the prediction of transition metal complex geometries. Together with the data obtained for $3 \mathrm{~d}$ and $4 \mathrm{~d}$ transition metal species ${ }^{7,8}$ a rather comprehensive set of data has been assembled that documents the strengths and weaknesses of modern DFT methods for the prediction of transition metal geometries. It turns out that no single functional is clearly superior to all others and hence, a variety of choices remains possible. Overall, there is a slight advantage of hybrid functionals, especially PBE1 (sometimes also called PBE0) and B3P86 or B3PW91 appear to be the most advantageous choices. Since PBE1 has also been found to perform exceedingly well for many other properties including energetics, ${ }^{78}$ excitation energies $^{79}$ or EPR properties, ${ }^{80}$ it may even be preferred over B3LYP for general chemistry applications. Nevertheless, very significant computational advantages can be realized if non-hybrid (GGA or meta-GGA) functionals are combined with the density fitting technique (a factor of 5-10 represents a typical speedup over conventional implementations). In this respect, the excellent behavior of the PBE functional should be mentioned as a viable alternative. However, it is clearly necessary to proceed to basis sets of at least triple-zeta quality if accurate results are to be obtained. Small, 
unpolarized basis sets such as LANL2DZ ${ }^{3}$ cannot be recommended if it is desired that the results reflect the properties of the functional more than the shortcomings of the basis set used. The extended study also demonstrates that well designed ECPs, such as the Stuttgart/Dresden ones, ${ }^{4}$ can safely be used for studying transition metal complex geometries. All-electron calculations are now equally feasible since suitable segmented Gaussian basis sets of various double-through quadruplezeta quality are available. ${ }^{19-22}$ Their performance in conjunction with the ZORA or DKH2 scalar relativistic treatments is very similar as in the ECP case without an undue increase in computation time. The exception are hybrid DFT calculations on 5d species where the significant number of fprimitives required to describe the 4f-shell properly does add noticeably to the computational effort. No such bottlenecks arise in nonhybrid calculations within the density fitting approximation, in particular if the efficient Split-RI-J variant is used that behaves particularly well with respect to higher angular momentum basis functions. ${ }^{81}$ The advantages of the all-electron treatment become significant upon calculating molecular properties such as total electron-densities, ${ }^{11}$ Mössbauer spectra, ${ }^{13}$ X-ray absorption spectra, ${ }^{12}$ NMR,${ }^{14}$ or EPR spectra. ${ }^{15,16}$ 


\section{Acknowledgments}

M.B. wishes to thank EaStChem for support and H. Früchtl for technical assistance. Computations were performed on a Fujitsu Siemens PC and an Opteron PC cluster at the University of St. Andrews. We acknowledge financial support by the university of Bonn as well as the SFB 624, the SFB 663 and the priority program 1137. We also thank Mr. Jens Mekelburger for technical assistance

\section{Supporting Information Available}

Bond distances of the $5 \mathrm{~d}$ test set in Table 1 and of the $3 \mathrm{~d}$ and $4 \mathrm{~d}$ test sets, optimized at selected levels, and PBE1/qzvp optimized geometries of the $5 \mathrm{~d}$ set. This material is available free of charge via the Internet at http://pubs.acs.org.

\section{References}

(1) See for instance: Dolg, M., in: Modern Methods and Algorithms of Quantum Chemistry, Proceedings, Second Edition (Ed.: Grotendorst, J.), NIC Series Vol. 3, John von Neumann Institute for Computing, Jülich (Germany), 2000, pp. 507-540 [www.fz-juelich.de/nicseries/Volume3/dolg.pdf], and the extensive bibliography cited therein.

(2) E.g., Frenking, G.; Antes, I.; Böhme, M.; Dapprich, S.; Ehlers, A. W.; Jonas, V.; Neuhaus, A.; Otto, M.; Stegmann, R.; Veldkamp, A.; Vyboishchikov, S. F., in: Reviews in Computational Chemistry, Vol. 8 (Eds.: Lipkowitz, K. B.; Boyd, D. B), VCH Publishers, New York, 1996, pp. 63144.

(3) Hay P. J.; Wadt, W. R. J. Chem. Phys. 1985, 82, 299-310.

(4) Dolg, M.; Wedig, U.; Stoll H.; Preuss, H. J. Chem. Phys. 1987, 86, 866-872.

(5) Helgaker, T.; Gauss, J.; Jørgensen, P.; Olsen, J. J. Chem. Phys. 1997, 106, 6430-6440.

(6) Bak, K. L.; Gauss, J.; Jørgensen, P.; Olsen, J.; Helgaker, T.; Stanton, J. F. J. Chem. Phys. 2001, 114, 6548-6556.

(7) (a) Bühl M.; Kabrede, H. J. Chem. Theory Comput. 2006, 2, 1282-1290. (b) Waller, M. P.; Bühl, M. J. Comp. Chem. 2007, 28, 1531-1537.

(8) Waller, M. P.; Braun, H.; Hojdis, N.; Bühl, M. J. Chem. Theor. Comput. 2007, 3, 22342242.

(9) van Lenthe, E.; Snijders, J. G.; Baerends, E. J. J. Chem. Phys. 1996, 105, 6505-6516.

(10) van Wüllen, C.; Langermann, N. J. Chem. Phys. 2007, 126, 114106.

(11) Vyboishchikov, S. F.; Frenking, G. J. Comput. Chem. 1997, 18, 416-429. 
(12) (a) DeBeer-George, S.; Petrenko, T.; Neese, F. Inorg. Chim. Acta 2008, 361, 965-972, (b) DeBeer-George, S., Petrenko, T.; Neese, F., submitted to J. Phys. Chem.; (c) Ray, K.; Petrenko, T.; Wieghardt, K.; Dalton Trans. 2007, 1552-1566; (d) Kokatam, S.; Ray, K.; Pap, J.; Bill, E.; Geiger, W.E.; LeSuer, R.J.; Rieger, P.H.; Weyhermüller, T.; Neese, F.; Wieghardt, K. Inorg. Chem. 2007, 46, 1100-1111; (e) Ray, K.; DeBeer-George, S.; Solomon, E.I.; Wieghardt, K.; Neese, F. Chem. Eur. J. 2007, 13, 2783-2797; (f) Kapre, R.; Ray, K.; Sylvestre, I.; Weyhermüller, T.; DeBeerGeorge, S.; Neese, F.; Wieghardt, K. Inorg. Chem. 2006, 45, 3499-3509.

(13) (a) Neese, F. Inorg. Chim. Acta 2002, 337C, 181-192; (b) Sinnecker, S.; Slep, L.; Bill, E.; Neese, F. Inorg. Chem. 2005, 44, 2245-2254; (c) Ray, K.; Begum, A; Weyhermüller, T.; Piligkos, S.; van Slageren, J.; Neese, F.; Wieghardt, K. J. Am. Chem. Soc. 2005, 127, 4403-4415; (d) Ray, K.; Weyhermüller, T.; Neese, F.; Wieghardt, K. Inorg. Chem. 2005, 44, 5345-5360.

(14) For some recent reviews see e.g.: (a) Bühl, M. Ann. Rep. NMR Spectrosc., in press.; (b) Autschbach, J. Coord. Chem. Rev. 2007, 251, 1796-1821. (c) Autschbach, J. Struct. Bonding 2004, $112,1-48$.

(15) (a) Fritscher, J.; Hrobarik, P.; Kaupp, M. J. Phys. Chem. B 2007, 111, 4616-4629; (b) Munzarova, M.; Kaupp, M. J. Phys. Chem. A 1999, 103, 9966-9983.

(16) (a) Neese, F. J. Chem. Phys. 2001, 115, 11080-11096; (b) Neese, F. J. Chem. Phys. 2003, 117, 3939-3948; (c) Neese, F. J. Chem. Phys. 2007, 127, 164112; (d) Neese, F. J. Am. Chem. Soc. 2006, 128, 10213-10222; (e) Sun, X.; Chun, H.; Hildenbrand, K.; Bothe, E.; Weyhermüller, T.; Neese, F.; Wieghardt, K. Inorg. Chem. 2002, 41, 4295-4303.

(17) Hess, B. A.; Marian, C. M. in Jensen, P.; Bunker, P.R. (Eds.), Computational Molecular Spectroscopy. John Wiley \& Sons, New York, 2000, p. 169ff.

(18) (a) Heully, J. L.; Lindgren, I.; Lindroth, E.; Martenssonpendrill, A. M. Phys. Rev. A 1986, 33, 4426-4429; (b) van Lenthe, J. G.; Baerends, E. J.; Snijders, E. J. Chem. Phys. 1993, 99, 45974610; (c) van Wüllen, C J. Chem. Phys. 1998 109, 392-399.

(19) Pantazis, D. A.; Chen, X.-Y.; Landis, C. R.; Neese, F. J. Chem. Theory Comput. 2008, 4, 908-919.

(20) Schäfer, A.; Horn, H.; Ahlrichs, R. J. Chem. Phys. 1992, 97, 2571-2577.

(21) Schäfer, A.; Huber, C.; Ahlrichs, R. J. Chem. Phys. 1994, 100, 5829-5835.

(22) Weigend, F.; Furche, F.; Ahlrichs, R. J. Chem. Phys. 2003, 119, 12753-12762.

(23) Landolt-Börnstein, Structure Data of Free Polyatomic Molecules (Ed.: Kuchitsu, K.), New Series, Vol. II/25, Springer Verlag, Berlin, 1998. 
(24) (a) Ruud, K. ; Åstrand, P.-O,; Taylor, P. R. J. Chem. Phys. 2000, 112, 2668-2683. (b) Ruud, K. ; Åstrand, P.-O,; Taylor, P. R. J. Am. Chem. Soc. 2000, 123, 4826-4833. (c) Ruden, T.; Lutnæss, O. B.; Helgaker, T. J. Chem. Phys. 2003, 118, 9572-9581.

(25) (a) Barone V. J. Chem. Phys. 2004, 120, 3059-3065. (b) Barone, V. J. Chem. Phys. 2005, $122,014108$.

(26) The equilibrium distance, $r_{e}$, is the distance between the positions of the nuclei on the potential energy surface, as obtained from standard geometry optimizations; $r_{g}$ is the average internuclear distance at temperature $\mathrm{T}, \mathrm{r}_{\mathrm{g}}{ }^{2}$ that at zero $\mathrm{K}$. It is the latter value that our computed effective geometries refer to. Typical quantities derived experimentally are $r_{a}$ (the effective internuclear distance as derived from electron scattering intensity), $r_{\alpha}$ (the distance between average nuclear positions in the thermal equilibrium at temperature $\mathrm{T}$ ), $\mathrm{r}_{\mathrm{z}}$ (the distance between average nuclear positions in the ground vibrational state), or $\mathrm{r}_{0}$ (the effective internuclear distance obtained from the rotational constants), see e.g.: Hargittai, I. in Stereochemical Applications of Gas-Phase Electron Diffraction, Part A: The Electron Diffraction Technique, Hargittai, I; Hargittai, M. (Eds.),VCH Publisher, Weinheim, pp.1-54 (1988).

(27) Gaussian 03, Revision D.01, M. J. Frisch, G. W. Trucks, H. B. Schlegel, G. E. Scuseria, M. A. Robb, J. R. Cheeseman, J. A. Montgomery, Jr., T. Vreven, K. N. Kudin, J. C. Burant, J. M. Millam, S. S. Iyengar, J. Tomasi, V. Barone, B. Mennucci, M. Cossi, G. Scalmani, N. Rega, G. A. Petersson, H. Nakatsuji, M. Hada, M. Ehara, K. Toyota, R. Fukuda, J. Hasegawa, M. Ishida, T. Nakajima, Y. Honda, O. Kitao, H. Nakai, M. Klene, X. Li, J. E. Knox, H. P. Hratchian, J. B. Cross, V. Bakken, C. Adamo, J. Jaramillo, R. Gomperts, R. E. Stratmann, O. Yazyev, A. J. Austin, R. Cammi, C. Pomelli, J. W. Ochterski, P. Y. Ayala, K. Morokuma, G. A. Voth, P. Salvador, J. J. Dannenberg, V. G. Zakrzewski, S. Dapprich, A. D. Daniels, M. C. Strain, O. Farkas, D. K. Malick, A. D. Rabuck, K. Raghavachari, J. B. Foresman, J. V. Ortiz, Q. Cui, A. G. Baboul, S. Clifford, J. Cioslowski, B. B. Stefanov, G. Liu, A. Liashenko, P. Piskorz, I. Komaromi, R. L. Martin, D. J. Fox, T. Keith, M. A. Al-Laham, C. Y. Peng, A. Nanayakkara, M. Challacombe, P. M. W. Gill, B. Johnson, W. Chen, M. W. Wong, C. Gonzalez, and J. A. Pople, Gaussian, Inc., Wallingford CT, (2004).

(28) Vosko, S. H.; Wilk L.; Nusair, M. Can. J. Phys. 1980, 58, 1200-1211. Functional III of that paper used.

(29) Becke, A. D. Phys. Rev. A, 1988, 38,3098-3100.

(30) Becke, A. D. J. Chem. Phys. 1996, 98, 5648-5642.

(31) a) Perdew, J. P. Phys. Rev. B 1986, 33, 8822-8824. b) Perdew, J. P. Phys. Rev. B, 1986, 34 , 7406. 
(32) Perdew, J. P. In Electronic Strucure of Solids, Ziesche, P.; Eischrig, H. Eds.: Akademie Verlag: Berlin (1991). b) Perdew, J. P.; Wang, Y. Phys. Rev. B 1992, 45, 13244-13249.

(33) Lee, C.; Yang W.; Parr, R. G. Phys. Rev. B 1988, 37, 785-789.

(34) Boese A. D.; Handy, N. C. J. Chem. Phys., 2001, 114, 5497-5503.

(35) (a) Perdew, J. P.; Burke, K.; Ernzerhof, M., Phys. Rev. Lett. 1996, 77, 3865-3868.

(36) Van Voorhis T.; Scuseria, G. E. J. Chem. Phys., 1998, 109, 400-410.

(37) (a) Tao, J. ; Perdew, J. P.; Staroverov V. N.; Scuseria, G. E. Phys. Rev. Lett., 2003, 91, 146401. (b) Tao, J.; Perdew, J. P.; Staroverov V. N.; Scuseria, G. E. Phys. Rev. Lett. 2004, 120, 6898-6911.

(38) (a) Staroverov, V. N.; Scuseria, G. E.; Tao, J.; Perdew, J. P. J. Chem. Phys. 2003, 119, 146401. b) Staroverov, V. N.; Scuseria, G. E.; Tao J.; Perdew, J. P. J. Chem. Phys. 2004, 121, 11507.

(39) Johnson, E. R.; Wolkow, R. A.; DiLabio, G. A. Chem. Phys. Lett. 2004, 394, 334-338.

(40) (a) Hehre, W. J.; Ditchfield, R.; Pople, J. A. J. Chem. Phys. 1972, 56, 2257-2261. (b)

Hariharan P. C.; Pople. J. A. Theor. Chim. Acta., 1973, 28, 213-222.

(41) Weigend, F.; Ahlrichs, R. Phys. Chem. Chem. Phys. 2005, 7, 3297-3305.

(42) Neese, F. ORCA - an ab initio, Density Functional and Semiempirical Program Package, 2.6-35; Universität Bonn: Bonn, Germany, 2008.

(43) van Lenthe, E.; Faas, S.; Snijders, J. G. Chem. Phys. Lett. 2000, 328, 107-112.

(44) (a) Grimme, S. J. Comput. Chem. 2004, 25, 1463-1476; (b) Grimme, S. J. Comput. Chem. 2006, 27, 1787-1799.

(45) E.g., the eclipsed form is more stable than the staggered one by $3.7 \mathrm{kcal} / \mathrm{mol}$ and 4.3 $\mathrm{kcal} / \mathrm{mol}$ at BP86/SDD and B3LYP/SDD levels, respectively.

(46) Girichev, G. V.; Petrov, V. M.; Giricheva, N. I.; Utkin, A. N.; Petrova, V. N. Russ. J. Struct. Chem. 1981, 22, 694.

(47) Borisenko, K. B.; Downs, A. J.; Robertsen, H. E.; Rankin, D. W. H.; Tang, C. Y. Dalton Trans. 2004, 967-970.

(48) (a) Faegri Jr., K.; Haaland, A.; Martinsen, K.-G.; Strand, T. G.; Volden, H. V.; Swang, O.; Anderson, C.; Persson, C.; Bogdanovic, S.; Herrmann, W. A. J. Chem. Soc. Dalton Trans. 1997, 1013-1018; (b) for an earlier study see: Ischenko, A. A.; Strand, T. G.; Demidov, A. V.; Spiridonov, V. P. J. Mol. Struct. 1978, 43, 227.

(49) Kadel, J.; Oberhammer, H. Inorg. Chem. 1994, 33, 3197-3198.

(50) Richardson, A. D.; Hedberg, K.; Lucier, G. M. Inorg. Chem. 2000, 39, 2787-2793.

(51) Robiette, A. G.; Hedberg, K.; Hedberg, L. J. Mol. Struct. 1977, 37, 105-112. 
(52) Page, E. M.; Rice, D. A.; Hagen, K.; Hedberg, L.; Hedberg, K. Inorg. Chem. 1982, 21, 3280.

(53) (a) original GED study assuming $D_{3 h}$ symmetry: Haaland, A.; Hammel, A.; Rypdal, K.; Volden, H. V. J. Am. Chem. Soc. 1990, 112, 4547-4549; (b) an irregular prism with two nonequivalent sets of W-C distances differing by ca. 6 - 8 pm has been found in the solid state: Kleinhenz, S.; Pfennig, V.; Seppelt, K. Chem. Eur. J. 1998, 4, 1687-1691; and (c) by means of DFT computations: Kaupp, M. Chem. Eur. J. 1998, 4, 1678-1686.

(54) Arnesen, S. P.; Seip, H. M. Acta Chem. Scand. 1966, 20, 2711.

(55) MW, r $\mathrm{r}_{0}$ value: Tackett, B. S.; Karunatilaka, C.; Daly, A. M.; Kukolich, S. G. Organometallics 2007, 26, 2070-2076.

(56) Giricheva, N. I.; Girichev, G. V.; Lapshina, S. B.; Shl'ykov, S. A.; Politov, Yu. A.; Butskii, V. D.; Pervov, V. S.; Russ. J. Struct. Chem. (Engl. Transl.) 1993, 34, 214-224.

(57) Hagen, K.; Hobson, R. J.; Rice, D. A.; Turp, N. J. Mol. Struct. 1985, 128, 33-40.

(58) GED values from (a) Herrmann, W. A.; Kiprof, P.; Rypdal, K.; Tremmel, J.; Blom, R.; Alberto, R.; Behm, J.; Albach, R. W.; Bock, H.; Solouki, B.; Mink, J.; Lichtenberger, D.; Gruhn, N. E. J. Am. Chem. Soc. 1991, 113, 6527-6537; MW results ("best fit" values for $\mathrm{Re}=\mathrm{O}$ and $\mathrm{Re}-\mathrm{C}$ distances of 170.3(2) and 207.4(4) pm, respectively) see (b) Wikrent, P.; Drouin, B. J.; Kukolich, S. G.; Lilly, J. C.; Ashby, M. T.; Herrmann, W. A. J. Chem. Phys. 1997, 107, 2187-2192.

(59) MW, $\mathrm{r}_{0}$ structure: Kukolich, S. G.; Drouin, B. J.; Indris, O.; Dannemiller, J. J.; Zoller, J. P.; Herrmann, W. A. J. Chem. Phys. 2000, 113, 7891-7900.

(60) Seip, H. M.; Stølevik, R. Acta Chem. Scand. 1966, 20, 385.

(61) Hagen, K.; Hobson, R. J.; Holwill, C. J.; Rice, D. A. Inorg. Chem. 1986, 25, 3659-3661.

(62) Huang, J.; Hedberg, K.; Pomeroy, R. K. Organometallics 1988, 7, 2049-2053.

(63) MW, r ro structure: Karunatilaka, C.; Tackett, B. S.; Washington, J.; Kukolich, S. G. J. Am. Chem. Soc. 2007, 129, 10522-10530.

(64) Ritz, C. L.; Bartell, L. S. J. Mol. Struct. 1976, 31, 73-76.

(65) MW, $\mathrm{r}_{0}$ structure: Evans, C. J.; Reynard, L. M.; Gerry, M. C. L. Inorg. Chem. 2001, 40, 6123-6131.

(66) Haaland, A.; Hougen, J.; Volden, H. V.; Puddephatt, R. J. J. Organomet. Chem. 1987, $325,311-315$.

(67) MW, r r structure: Walls, C.; Lister, D. G.; Sheridan, J. J. Chem. Soc. Farad. Trans. II 1975, 71, 1091-1099.

(68) Oberhammer, H. J. Mol. Struct. 1978, 48, 389-394.

(69) MW: Rego, C. A.; Cox, A. P. J. Chem. Phys. 1988, 89, 124-128. 
(70) A notable underestimation of this bond length has also been noted at the MP2/LANL/6$3+\mathrm{G}^{*}$ level, from which some geometrical and force-field parameters have been used during refinement of the GED data, cf. reference 47. In that paper an unusually high vibrational amplitude has been noted for this bond and has been attributed to a fluxional process exchanging bridging and terminal $\mathrm{H}$ atoms. If the potential energy surface for this process were highly anharmonic with a very low barrier, a theoretical description of the light $\mathrm{H}$ atoms might require quantum dynamical methods; however, we could find no evidence for this, because a notable barrier of $6.9 \mathrm{kcal} / \mathrm{mol}$ and $5.9 \mathrm{kcal} / \mathrm{mol}$ is indicated at the BP86/SDD and B3LYP/SDD levels, respectively (including zeropoint energies), proceeding via a $\mathrm{Hf}\left(\eta^{3}-\mathrm{BH}_{4}\right)_{3}\left(\eta^{2}-\mathrm{BH}_{4}\right)$ transition state.

(71) Toyama, M.; Oka, T.; Morino, Y. J. Mol. Spectrosc. 1964, 13, 193-213.

(72) Only minor improvements are brought about by the use of an f-function on the metal (taken from: Hollwart, A.; Böhme, M.; Dapprich, S.; Ehlers, A. W.; Gobbi, A.; Jonas, V.; Kohler, K. F.; Stegmann, R.; Veldkamp, A.; Frenking, G. Chem. Phys. Lett. 1993, 208, 237-240; Chem. Phys. Lett. 1994, 224, 603).

(73) Very recently, and after this work was started, more flexible basis sets have been devised for the Hay-Wadt ECPs, the combination thereof denoted LANL2TZ (Roy, L. E.; Hay, P. J., Martin, R. L. J. Chem. Theory Comput., in press, DOI 10.1021/ct8000409).

(74) See Koch, W.; Holthausen, M. C. A Chemist's Guide to Density Functional Theory, 2nd $E d$., Wiley-VCH, Weinheim, 2001, and the extensive bibliography therein.

(75) Because we had not tested the PBE1 functional, which performs so well for the geometries of the heavier metal complexes, in our initial study on the $3 \mathrm{~d}$ congeners, we have now reoptimized the latter set at the PBE1/AE1 level. For this set alone, this level affords mean and standard deviations of $-1.4 \mathrm{pm}$ and $1.7 \mathrm{pm}$, respectively, for the equilibrium geometries, and $-0.9 \mathrm{pm}$ and $1.77 \mathrm{pm}$, respectively, for the effective geometries.

(76) The rovibrational corrections for $\mathrm{Co}(\mathrm{CO})_{3}(\mathrm{NO})$ were erroneously given as zero in Table 1 of reference $7 \mathrm{~b}$, whereas they should read $0.45 \mathrm{pm}$ and $0.64 \mathrm{pm}$ for the $\mathrm{Co}-\mathrm{N}$ and Co-C bonds, respectively. We apologize for this oversight, which affects the final assessment of the whole set only marginally, and does not alter any of the qualitative conclusions.

(77) (a) Neese, F J. Biol. Inorg. Chem. 2006, 11 702-711; (b) Neese, F. Coord.Chem. Rev. 2008, in press.

(78) Grimme, S. J. Phys. Chem. A 2005, 109, 3067-3077.

(79) (a) Adamo, C.; Scuseria, G. E.; Barone, V. J. Chem. Phys. 1999, 111, 2889-2899. (b) Adamo, C.; Barone, V. Theor. Chem. Acct. 2000, 105, 169-172. 
(80) (a) Neese, F. J. Chem. Phys. 2001, 115, 11080; (b) Koßmann, S.; Kirchner, B.; Neese, F. Mol. Phys. 2007, 105, 2049-2071.

(81) Neese, F. J. Comp. Chem. 2003, 24, 1740-1747. 
